\title{
Is performance in goal oriented head movements altered in patients with tension type headache?
}

\author{
Andrée-Anne Marchand ${ }^{1}$, Vincent Cantin ${ }^{1}$, Bernadette Murphy², Paula Stern ${ }^{3}$ and Martin Descarreaux ${ }^{1 *}$
}

\begin{abstract}
Background: Head repositioning tasks have been used in different experimental and clinical contexts to quantitatively measure motor control performance. Effects of pain on sensorimotor control have often been described in various musculoskeletal conditions and may provide relevant information with regard to potential mechanisms underlying tension-type headaches. The purpose of the current study was to compare the performance of patients with tension-type headache and healthy participants in a cervical aiming task using the Fitts' task paradigm.

Methods: Patients with tension-type headache and healthy controls were compared in a cervical aiming task. Participants were asked to move their head as quickly, and precisely as possible to a target under various experimental conditions. Dependent variables included movement time, variable error, constant error and absolute error.

Results: As predicted by Fitts' law, decreasing target size and increasing head rotation amplitudes yielded longer movement times in both groups. Participants with tension-type headache, when compared to healthy participants showed a significant increase in both constant and absolute errors for each of the four conditions.

Conclusion: Decreased motor performance was observed in participants with tension-type headache, likely due to altered motor control of the neck musculature. Future research is warranted to investigate the clinical aspect related to decrease in motor performance.
\end{abstract}

Keywords: Tension type headaches, Motor control, Cervical spine, Kinesthetic sense

\section{Background}

Tension-type headache (TTH), is defined as episodes of bilateral cephalic pain, characterized as "band-like" pressing or tightening sensation of mild to moderate intensity which may or may not be associated with pericranial tenderness on manual palpation [1]. According to a review of population based studies, the worldwide point prevalence of headache can be estimated at $47 \%$, of which $38 \%$ is attributed to TTH [2]. This is the most common type of primary headache with lifetime prevalence in the general population ranging from 30 to $86 \%[1,3]$. Furthermore, frequent episodic and chronic TTH are reported significantly more frequently in women than men [4], causing greater disability and leading patients to seek care [5].

Despite advances in the understanding of TTH, controversy exists in the literature regarding its aetiology and best management strategies [6,7]. The diagnosis of

\footnotetext{
* Correspondence: martin.descarreaux@uqtr.ca

${ }^{1}$ Université du Québec à Trois-Rivières, 3351 boul. des Forges, C.P. 500

Trois-Rivières, Québec G9A 5H7, Canada

Full list of author information is available at the end of the article
}

TTH is primarily based on clinical signs and symptoms gathered through history taking. Although pericranial tenderness is considered a facultative criterion to the diagnosis of TTH, there has been no objective physical outcome measure systematically proposed to help clinicians with the diagnosis. Physiological outcome measures are commonly studied in individuals with low back or cervical pain $[8,9]$ and have been used effectively to discriminate healthy controls from symptomatic patients with these conditions [9-11]. Furthermore, a recent scoping review on musculoskeletal physical outcome measures in individuals with TTH has highlighted the scarce use of such data in clinical research [12]. While both myofascial pain detection and tolerance thresholds are consistently decreased in patients with TTH [13] suggestive of central sensitization [14], other commonly used outcomes such as presence of trigger points, muscle cross sectional area, level of muscle activity and cervical range of motion yielded mixed results [12]. 
Investigations into the effect of musculoskeletal conditions on sensorimotor control suggest that patients experiencing pain develop motor adaptations as a way to alleviate symptoms [15]. It is proposed that if the motor adaptation is excessive or persists past the painful episode, it contributes to the perpetuation or recurrence of pain [15]. Thus, muscular control is at the center of several models that aim to understand motor planning and response in patients experiencing pain [16]. Changes in sensorimotor function have been shown to have profound effects on control of movement in many painful conditions of the musculoskeletal system such as neck pain [17], low back pain [18] and shoulder pain [19]. Alterations in sensorimotor functions include reduced sensory acuity [20], reduced responsiveness to sensory input, reorganisation of the sensory cortex and smudging of motor regions of the brain [21-23], and increased errors in position sense [24]. Such modifications have been observed in the cervical region of patients with whiplash associated disorders and nonspecific subclinical neck pain who displayed decreased kinaesthetic sense when tested in a cervical aiming task [25-27].

Cervical repositioning accuracy tasks measure the ability of the neuromuscular system to actively reposition the head in a given posture after active movements in different planes of movement. It is generally accepted that the receptors primarily responsible for joint position sense are the muscle spindles. Muscle spindles are found in very high density in the deeper cervical muscles of the upper cervical spine such as the sub occipital complex (superior oblique capitis, inferior oblique capitis and rectus capitis posterior major and minor) when compared with lower cervical spine [28,29]. In addition, the relatively low number of mechanoreceptors found in human cervical facet joint capsules suggests a complementary role to that of muscle receptors in the mediation of position sense, particularly at the end of motion ranges [30]. The afferent input derived from muscle, cutaneous and joint receptors along with information from the vestibular and visual systems are all together integrated to build an internal reference frame of the musculoskeletal system and to recalibrate it [30,31]. Consequently, a cervical spine positioning error is considered to mainly reflect disturbed afferent input from the articulations of the neck and muscle receptors [32].

The cervical kinaesthetic task developed by Revel in 1991 and modified by Loudon in 1997 has shown to be a valid and reliable measure of the cervical sensorimotor control [33-35] and has been commonly used in whiplash associated disorders $[17,36]$ and nonspecific neck pain populations [37]. Motor performance of the cervical spine has also been established through the measurement of movement time when engaged in a Fitts' task experiment [37-39]. Fitts' task experiment is derived from the speed accuracy trade-off in target-constrained aiming situations. The Fitts' law states that as target size decreases or as amplitude between targets increases, the movement time will increase linearly [40]. It is considered a reliable descriptor of the information processing demands associated with a variety of aiming movements [41]. Since movement time dictates the type of feedback corrections that are possible and the relative contribution of different movement control mode, increasing the index of difficulty provides information on how sensory information (target size and distance) is used to generate a motor response. The Fitts' task allows the assessment of motor skill performance and is particularly well suited for clinical studies, as performance during the task is resistant to learning effects [41].

A recent study has highlighted that chronic neck patients increase their movement time and use alternative control strategies in order to reduce response variability and be as accurate and consistent as possible in their performance [37].

Therefore, the purpose of the current study was to compare the performance of patients with $\mathrm{TTH}$ and healthy participants in a cervical aiming task using the Fitts' task paradigm.

Given the sensorimotor changes observed in neck pain populations under varying experimental models and the proposed implications of the cervical region to explain the pathophysiology of TTH, it is hypothesized that patients with $\mathrm{TTH}$ have similar sensorimotor deficits and that theses will be positively correlated to clinical parameters.

\section{Methods}

\section{Participants}

All participants $(\mathrm{N}=33$; female $=85 \%)$ were recruited by convenience from the university community and employees. Given that there was no data available to conduct a standard sample size calculation, the sample size estimate was based on a similar study looking at kinematics in a head reorientation task using the Fitts' paradigm[37]. Inclusion criteria for TTH patients consisted of fulfilling the second version of the International Headache Society (IHS) classification criteria for primary tension type headache and to experience headache at least once per month. Participants of the control group were included on the basis that they were healthy and had no previous history of headaches. Inclusion and exclusion criteria are listed in Table 1. In order to take part to the experimental session the participants were screened for the presence of potential confounders such as an ongoing episode of headache, having received treatment in the past 72 hours, and wearing clothes that cover the neck. After this initial screening, participants provided written informed consent prior to 
Table 1 Inclusion and exclusion criteria

\begin{tabular}{|c|c|}
\hline Inclusion criteria & Exclusion criteria \\
\hline Tension-type headache subjects & Rheumatoid arthritis \\
\hline \multirow[t]{2}{*}{$\begin{array}{l}\text { Fulfilling criteria of the International Headache } \\
\text { Society (IHS) for TTH: }\end{array}$} & $\begin{array}{l}\text { Impairment of } \\
\text { vestibular system }\end{array}$ \\
\hline & Visual impairment \\
\hline Headache lasting from 30 minutes to 7 days & Hearing impairment \\
\hline $\begin{array}{l}\text { Headache has at least two of the following } \\
\text { characteristics: }\end{array}$ & $\begin{array}{l}\text { Other types of } \\
\text { headache }\end{array}$ \\
\hline 1. bilateral location & $\begin{array}{l}\text { Present episode of } \\
\text { headache }\end{array}$ \\
\hline 2. pressing/tightening (non-pulsating) quality & $\begin{array}{l}\text { Neck pain as main } \\
\text { complaint }\end{array}$ \\
\hline 3. mild or moderate intensity & Neck trauma \\
\hline $\begin{array}{l}\text { 4. not aggravated by routine physical activity } \\
\text { such as walking or climbing stairs }\end{array}$ & Active site of pain \\
\hline Both of the following: & $\begin{array}{l}\text { Chronic pain } \\
\text { syndrome }\end{array}$ \\
\hline 1. no nausea or vomiting (anorexia may occur) & $\begin{array}{l}\text { Whiplash associated } \\
\text { disorders }\end{array}$ \\
\hline \multicolumn{2}{|l|}{$\begin{array}{l}\text { 2. no more than one of photophobia or } \\
\text { phonophobia }\end{array}$} \\
\hline \multicolumn{2}{|l|}{ Not attributable to another disorder } \\
\hline \multicolumn{2}{|l|}{ Experiencing at least 1 episode/month } \\
\hline \multicolumn{2}{|l|}{ Control subjects } \\
\hline No headache & \\
\hline
\end{tabular}

demographic data collection and laboratory testing as approved by the Université du Québec à Trois-Rivières human ethics committee (certificate \# CER-12-181-06.23).

\section{Outcome measures}

Participants in the experimental group were questioned about the frequency of headache episodes and were asked to score the intensity of their typical headache prior to the experimental session using a $100 \mathrm{~mm}$ visual analog scale (VAS). A VAS score was also obtained from all participants after the experimental task to evaluate if any pain developed during the experimental session. The Neck disability index (NDI), the State-Trait Anxiety Inventory (STAI) and the Headache Impact Test (HIT-6) were used to respectively quantify neck disability, the strength of an individual's feelings of state and trait anxiety across typical situations, and the effect that headaches have on daily ability function. The French versions of the questionnaires which were used have all been validated [42-44]. Cervical ranges of motion were also quantified using a cervical range of motion (CROM) goniometer to ensure participants' ability to complete the experimental task [45]. Ranges of motion in all planes were measured twice and the mean value was recorded. The range of motion assessment was performed to ensure that all participants could reach $50^{\circ}$ of rotation and to identify potential differences between the two groups.

\section{Aiming task}

For this study, the Fitts' task paradigm was chosen to ensure that an optimal challenge point would be met in at least one of the experimental conditions. Index of difficulty variation [40] is often used to alter the functional level of a task to enhance differences between groups that may otherwise not be observed [37]. A custom made experimental set-up similar to that used in previous studies was developed to assess cervical kinesthetic performance [37]. A laser pointer mounted on a helmet was secured to the head and tightened enough to avoid extra movement yet still be comfortable for the participants. In a quiet and dimly lit room, participants were seated on a chair with back rest facing a black semicircular board at a radial distance of $1.75 \mathrm{~m}$. The seat height was adjusted so that the participants had their eyes level with the targets. Participants were instructed first to close their eyes and to produce a few nonmaximal flexion, extension and rotation head movements and then assume a neutral final position. This position was used as the starting point reference $\left(0^{\circ}\right)$ for every subsequent trial with the laser pointer oriented in the center of the board. Reference positions $\left(25^{\circ}\right.$ and $40^{\circ}$ ) were also recorded for each of the conditions in order to determine movement time, directional error, absolute error and variable error. The instructions provided at this point were standardized and always provided similarly for all participants. Participants were told to rotate their head as quickly and precisely as possible to the target, and then back to the neutral head position. Participants were asked not to attempt to correct the movement once it was initiated (this was to ensure that the movement was made without any correction based on sensory feedback during the pointing task). Four different conditions were represented by two target sizes (8 $\mathrm{cm}$ and $12 \mathrm{~cm}$ diameter), and two rotation amplitudes ( $25^{\circ}$ and $40^{\circ}$ from the neutral head position). The index of difficulty were calculated using the Fitts' law formula: $\left[\log _{2}(2 \mathrm{~A} / \mathrm{W})\right]$; where A represents movement amplitude, and $\mathrm{W}$ represents target width. The arc length corresponding to the axial rotation motion was calculated to obtain each index of difficulty. Index of difficulty of each of the four conditions was: condition 1 (3.67); condition 2 (4.25); condition 3 (4.35); condition 4 (4.93). Due to the repetitive nature of the experimental task and high concentration demand, arrangements had to be made to avoid any upsurge of headache. Therefore, participants were randomly asked to perform the four conditions on either right or left side of the board only. All conditions were conducted in a random order to control for potential sequence order effects. Each participant was allowed 
15 trials with eyes opened to familiarize with a given condition before the recording period consisting of 10 trials with eyes closed. Each trial was performed successively with approximately 5 seconds between each repetition. This process was repeated for each of the four conditions. Kinematic data were collected using an active marker motion analysis system (Optotrak Certus, Northern Digital, Waterloo, ON, Canada). Three lightemitting diodes positioned on the helmet were used to create a vector. Angular displacement of the head in the transverse plane was calculated by subtracting the initial angular position from the final angular position of the vector. Kinematic data was collected at $100 \mathrm{~Hz}$, and was low-pass filtered using a dual-pass, fourth-order Butterworth filter with a cut-off frequency set at $5 \mathrm{~Hz}$.

\section{Data analysis}

Dependent variables included movement time (MT), variable error (VE), constant error (CE) and absolute error (AE). Movement time is represented by the time required to move from resting position to the target. VE measures the inconsistency in movement outcome. It represents the difference between the participant's movement amplitude score on each trial and his or her own average score. CE represents the positive or negative difference between the amplitude reached and the target. A positive $\mathrm{CE}$ corresponds to overshooting the target while a negative CE corresponds to undershooting the target. AE represents the average absolute deviation (without regard to direction) between the participant's responses and the target. These four variables are commonly used as markers of motor performance during aiming task [46].

\section{Statistical analysis}

The statistical analysis was performed with Statistica data analysis software system, version 10 (StatSoft, Tulsa, OK, USA). Normality of distribution for every dependent variable was assessed with the Kolmogorov-Smirnov test and through visual inspection of data. T-tests for independent samples were conducted for baseline values of continuous variables. All dependent variables (MT, $\mathrm{CE}, \mathrm{VE}$ and $\mathrm{AE}$ ) were found to be normally distributed and were therefore submitted to a mixed model ANOVA, with Movement Amplitude $\left(25^{\circ}\right.$ and $\left.40^{\circ}\right)$ and Target Size $(8 \mathrm{~cm}$ and $12 \mathrm{~cm})$ as within-subject factors and Group as between-subject. Whenever a main or interaction effect was observed, post hoc comparisons were made using Tukey's test. Polynomial contrasts were also conducted to test for the linear trend in movement time (linear relationship between movement time and target index of difficulty). Effect size estimates were calculated by partial eta-squared $(\eta \mathrm{p} 2 ; 0.01=$ small effect; $0.06=$ medium effect; $0.14=$ large effect). In order to assess the association between clinical status and motor performance, simple correlation tests were performed separately for each clinical outcome (Intensity and Frequency of pain, HIT-6, NDI) and dependent variable (MT, CE, AE, VE). Statistical significance was set, for all analyses, at $\mathrm{p}<0.05$.

\section{Results}

A total of 33 participants were recruited for this study. The tension type headache group $(n=16)$ included individuals with either episodic or chronic tension type headache. Seventeen healthy participants without any prior history of headache or with less than two non disabling headache episodes per month and which had never been given a medical diagnosis were included in the study to form the control group. T-tests for independent samples revealed that both groups were comparable for age, weight, height and both STAI scores (all $p>0.05)$. A significant difference in baseline pain scores $(p=0.01)$, frequency of episodes $(p>0.0001)$, neck disability scores $(\mathrm{p}=0.0003)$ and headache impact scores $(60.0 \pm 9.2$ for the TTH group, N/A for control) was observed between the two groups. The total cervical range of motion for rotation and lateral flexion was similar in both groups ( $p>0.05$ ) whereas total range of motion for cervical flexion-extension $\left(125,7^{\circ} \pm 16,1^{\circ}\right)$ was significantly decreased in the TTH group $(\mathrm{p}=0.02)$. Participants' baseline characteristics and cervical range of motion are presented in Table 2.

The ANOVA revealed, as predicted by Fitts' law speed-accuracy trade-off principle, that decreasing target size and increasing head rotation amplitudes (increasing index of difficulty) yielded longer MT in both groups (see Table 3). However, no group difference could be identified ( $p>0.05$ ). Polynomial contrasts confirmed the significant linear trend $(\mathrm{p}<0.0001)$.

The ANOVA also revealed a significant group effect for both constant and absolute errors whereas no Group differences could be identified in movement time and variable error $(p>0.05)$. Patients with TTH showed significantly increased $\mathrm{CE}(\mathrm{F}(1,31)=4.22, \mathrm{p}=0.048, \eta \mathrm{p} 2=$ $0.12)$ and $\operatorname{AE}(F(1,31)=5.18, p=0.03, \eta p 2=0.14)$. Mean (SD) $\mathrm{CE}$ and $\mathrm{AE}$ for each group throughout all conditions are presented in Figures 1 and 2.

Neither Group x Target size nor Group x Movement amplitude interaction effect were present $(p>0.05)$ for any of the dependant variables. Mean (SD) values for all dependant variables in patients with $\mathrm{TTH}$ and healthy participants are presented in Table 3.

Moderate positive correlations were observed between $\mathrm{CE}$ and respectively TTH frequency $(\mathrm{r}=0.38, \mathrm{p}=0.03)$, NDI scores $(r=0.42, p=0.01)$ and HIT-6 scores $(r=0.34$, $\mathrm{p}=0.048)$. Moderate positive correlations were also identified between $\mathrm{AE}$ and TTH frequency $(\mathrm{r}=0.40, \mathrm{p}=0.02)$, 
Table 2 Participants' baseline characteristics and cervical range of motion

\begin{tabular}{lccccccc}
\hline & \multicolumn{2}{c}{$\begin{array}{c}\text { Group 1 (healthy } \\
\text { controls) }\end{array}$} & & \multicolumn{2}{c}{$\begin{array}{c}\text { Group 2 (patients } \\
\text { with TTH) }\end{array}$} & \\
\cline { 2 - 3 } & Mean & SD & & Mean & SD & p \\
\hline Age (years) & 30.4 & 7.9 & & 28.1 & 8.1 & 0.40 \\
Frequency/month & 0.4 & 0.4 & & 7.5 & 4.8 & $<0.001$ \\
Pain intensity (cm) & 3.6 & 2.2 & & 5.4 & 1.3 & 0.01 \\
Weight (kg) & 65.1 & 12.2 & & 67.2 & 11.5 & 0.60 \\
Height (cm) & 169.1 & 8.4 & & 166.3 & 7.6 & 0.32 \\
NDI (/50) & 1.9 & 4.1 & & 11.6 & 8.9 & $<0.001$ \\
HIT-6 (36-78) & 0 & - & & 60.0 & 9.1 & 0 \\
STAI - State (20-80) & 49.2 & 2.8 & & 48.1 & 4.1 & 0.38 \\
STAI - Trait (20-80) & 47.9 & 4.2 & & 47.1 & 4.2 & 0.56 \\
ROM flex-ext (deg) & 140.8 & 20.2 & & 125.7 & 16.1 & 0.02 \\
ROM rotation (deg) & 146.8 & 18.4 & & 138.3 & 16.1 & 0.16 \\
ROM lat. flexion (deg) & 91.8 & 17.2 & & 90.1 & 13.9 & 0.75 \\
\hline
\end{tabular}

NDI scores $(r=0.45, \mathrm{p}=0.009)$ and HIT-6 scores $(\mathrm{r}=0.40$, $\mathrm{p}=0.048)$.

\section{Discussion}

The objective of the present study was to compare the motor performance of patients with TTH and healthy participants using a cervical aiming task performed under the Fitts' law paradigm.

The main findings of this study indicated that patients with TTH show significantly decreased motor performance in an aiming task involving the cervical spine when compared to healthy adult controls. Although participants with TTH were able to reproduce head movements with similar movement time and variability, they were not as accurate as the healthy participants. Interestingly, headache frequency, cervical disability and headache related disability were moderately correlated to both $\mathrm{CE}$ and $\mathrm{AE}$ indicating that changes in sensorimotor control of the head and neck movement may increase with flare-ups or chronification of TTH. The index of difficulty and movement time relationship observed during the cervical aiming task yielded similar results to those reported in previous Fitt's task studies involving the cervical spine. Indeed, increasing the difficulty index by modulating target sizes and rotational movement amplitudes yielded increased movement time, consistent with the linear speed-accuracy trade-off principle $[37,39,40,47]$. In fact, increases in movement time for the most challenging condition yielded a more accurate performance in both groups, although such difference was not statistically significant. Using increasing levels of difficulty forces participants into a compromise where feedback, under difficult circumstances, must be integrated to provide an appropriate response. In the present
Table 3 Mean (SD) values for all dependant variables

\begin{tabular}{|c|c|c|c|c|c|}
\hline & & \multicolumn{2}{|c|}{$\begin{array}{l}\text { Group } 1 \\
\text { (healthy } \\
\text { controls) }\end{array}$} & \multicolumn{2}{|c|}{$\begin{array}{l}\text { Group 2 } \\
\text { (patients } \\
\text { with TTH) }\end{array}$} \\
\hline & & Mean & SD & Mean & SD \\
\hline \multirow[t]{4}{*}{ Movement time (ms) } & Condition 1 & 551 & 45 & 567 & 37 \\
\hline & Condition 2 & 518 & 37 & 562 & 33 \\
\hline & Condition 3 & 592 & 42 & 594 & 39 \\
\hline & Condition 4 & 615 & 41 & 646 & 49 \\
\hline \multirow[t]{4}{*}{ Constant error (deg) } & Condition 1 & 3.4 & 0.9 & 9.4 & 2.6 \\
\hline & Condition 2 & 2.9 & 1.1 & 8.3 & 2.3 \\
\hline & Condition 3 & 4.8 & 1.0 & 7.2 & 1.8 \\
\hline & Condition 4 & 1.5 & 1.3 & 4.5 & 2.2 \\
\hline \multirow[t]{4}{*}{ Absolute error (deg) } & Condition 1 & 4.5 & 0.7 & 10.5 & 2.4 \\
\hline & Condition 2 & 5.1 & 0.6 & 9.1 & 2.1 \\
\hline & Condition 3 & 5.8 & 0.7 & 8.7 & 1.4 \\
\hline & Condition 4 & 5.4 & 0.6 & 8.9 & 1.9 \\
\hline \multirow[t]{4}{*}{ Variable error (deg) } & Condition 1 & 2.9 & 0.2 & 4.0 & 0.5 \\
\hline & Condition 2 & 3.4 & 0.2 & 3.4 & 0.4 \\
\hline & Condition 3 & 3.1 & 0.3 & 3.4 & 0.3 \\
\hline & Condition 4 & 3.4 & 0.2 & 4.4 & 1.5 \\
\hline
\end{tabular}

Condition 1: $25^{\circ}, 12 \mathrm{~cm}$; condition 2: $25^{\circ}, 8 \mathrm{~cm}$; condition $3: 40^{\circ}, 12 \mathrm{~cm}$; condition 4: $40^{\circ} 8 \mathrm{~cm}$

study, participants performed the task slower in order to meet the precision criteria.

To the best of our knowledge, this study is the first to document cervical sensorimotor performances in individuals with TTH. Studies of head repositioning accuracy conducted in cervicogenic headache and migraine populations have found no difference between symptomatic and control participants $[16,48,49]$. Distinct pathophysiological features between TTH and other types of headache and the fact that these early studies were not designed to primarily assess motor performance, may in part account for these differences. Although the joint positioning error is commonly tested with the subjects relocating their head to a neutral posture following active cervical movements $[17,26]$ our method appears to be adequate to test sensorimotor dysfunction in patients with cervical musculoskeletal conditions. Modulating the difficulty index of a motor task may prove to be of particular interest to detect subtle deficits in various clinical populations.

The impairment of motor performance in a TTH population, suggests underlying changes in afferent input from the cervical muscles which may only become apparent in conditions where visual input is unavailable or unreliable and vestibular input insufficient to perform the task accurately.

Results of the current study highlight the potential benefit of motor control training rehabilitation protocol 


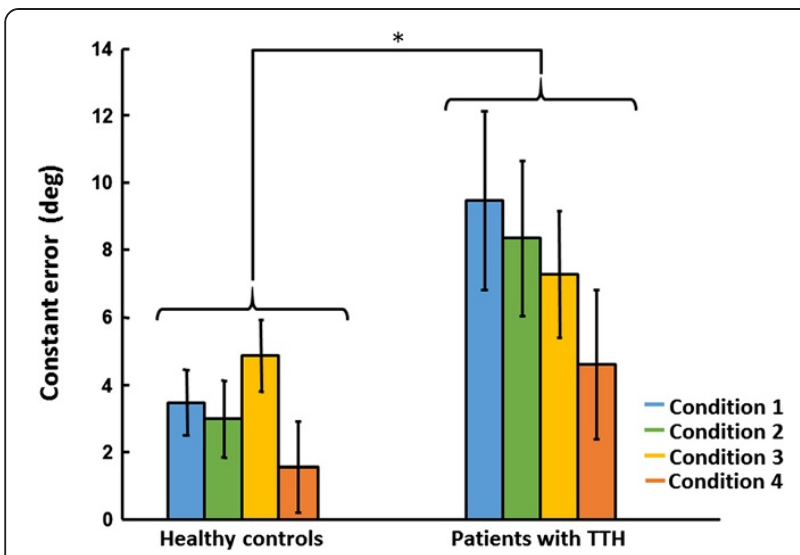

Figure 1 Mean (SD) constant errors for each group throughout all conditions.

in the treatment of patients with TTH such as the one suggested by Van Ettekoven et al. [50]. Given the significant differences observed for all four level of difficulty, a simpler version of the test could be developed to identify and monitor cervical sensorimotor changes in the experimental or clinical setting.

Available ROM may be a limiting mechanical factor influencing motor performance in a cervical aiming task. The values recorded for cervical ROM in the various movement planes were similar to the age-dependent values reported in a healthy population even though the baseline values were significantly different between the TTH group and the healthy participant group for the flexion-extension range [51]. Among the few studies looking at ROM in populations with TTH, decreases in ROM are reported to be variable [12]. As such, previous studies have described active cervical flexion as decreased in patients with TTH and active extension as being similar to healthy controls. Overall, patients with TTH involved in

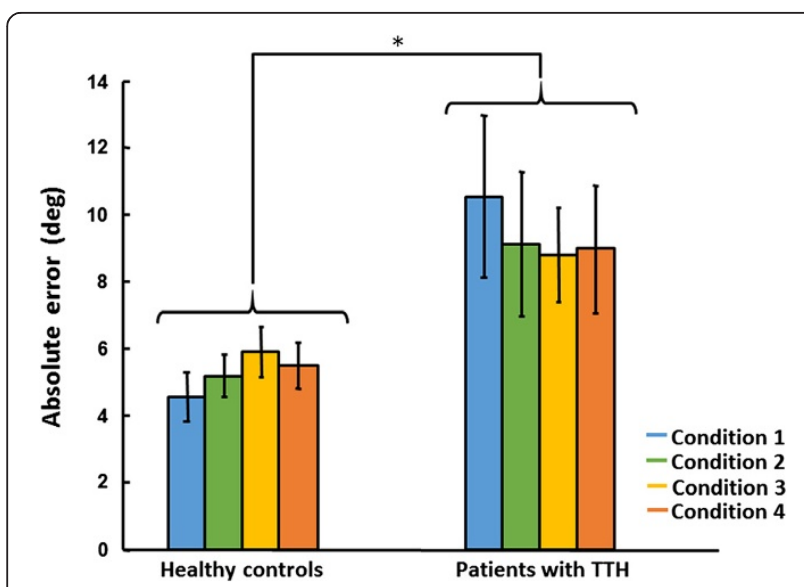

Figure 2 Mean (SD) absolute errors for each group throughout all conditions. this study presented with significant decreases in both flexion and extension ROM which could not be explained by presence of pain neither by age or gender differences between groups. These differences, however, may have only limited impact during head rotation and cannot explain the decreased motor performance in an aiming task observed in patients with TTH.

It has been suggested that sensorimotor deficits associated with painful conditions could be explained by changes at multiple levels of the motor system leading to altered mechanical behaviour and redistribution of muscles activity with the aim to protect from further pain or injury [15]. Possible central pathophysiological mechanisms of TTH include central sensitization of nociceptive circuits and impaired supraspinal descending inhibitory control of pain [52]. Changes in cervical muscle electromyographic activity have also been described but remain controversial and perhaps a distinctive features of episodic TTH [12]. From an anatomical perspective, preliminary studies have identified fibrous connections travelling through the atlantoaxial interspace [53] which may impact dural tension during movements of the atlantooccipital and atlanto-axial vertebral joints and result in a variety of clinical manifestations [54]. Whether or not these structures and physiological mechanisms play a significant role in TTH remains to be determined.

\section{Limitations}

In the present study, patients presented with fairly good functional status and a limited number of patients with severe TTH were included $(\mathrm{N}=5)$. Therefore, the participants involved in the present study represent a subgroup of patients with TTH which might explain the lack of clear associations between the clinical parameters and physical outcomes. Higher levels of pain and disability may lead to distinctive features of sensorimotor adaptation which might not have been identified in this study. Furthermore, inclusion of healthy controls with a prior history of headache may tamper the differences identified between the two groups. However, considering that the lifetime prevalence of TTH in the general population can reach up to $86 \%$ and is likely to affect most individuals at least once, the participants are estimated to be a fair representation of the general population.

The vestibular system plays an important role in maintaining an accurate representation of self-motion. Indeed, the vestibular system provides a veridical representation of head motion to higher-order centers for the perception of self-motion and spatial memory [55]. Although participants in our study were screened for potential vestibular disorders, we cannot exclude the possibility that the activation of the vestibular system occurred during rapid head movement, therefore contributing to task performance optimization. Future research settings 
should include perturbation of the vestibular system in order to tease out the contribution of the different sensory inputs.

It is also possible that fatigue or attentional disruption may have played a role in the participants' performance. However, a recent article by Moore et al. [56] investigating attentional disruption in patients with headache emphasized that headache pain appears to impair general task performance, irrespective of task complexity, rather than specific attentional mechanisms. Thus, in light of these results, we believe that the effect of pain on attention was limited by conducting all experimental sessions when TTH patients were not in an ongoing headache episode.

Due to its nature, a cross-sectional study does not allow for an assessment of the temporality of association. Longitudinal studies will be required to determine which of the TTH symptoms or impaired motor performance came first.

Future research should focus on evaluating the association between different stages of clinical disability and the associated motor adaptations. Identifying clinical and physiological factors involved in the transition from episodic to chronic TTH is a key issue in the development of original conservative approaches. A better understanding of the physiological mechanisms underlying motor adaptations in TTH populations will certainly inform both evaluation and clinical interventions as part of rehabilitation protocols.

\section{Conclusion}

The results from the present study indicate that performance in goal oriented head movement is decreased in individuals with TTH when compared to healthy participants. Peripheral mechanisms described as myofascial nociception and central mechanisms leading to sensitization and inadequate endogenous pain control are becoming well-recognized components of TTH pathophysiology, whereas anatomical studies have provided an understanding for the implication of cervical muscles in motor control. The increasing body of information related to sensorimotor adaptations in painful conditions should therefore shed light on functional limitations associated with primary headaches. Future research, however, is warranted to investigate the clinical aspect related to decrease in motor performance.

\section{Competing interest}

The authors declare that they have no competing interests.

\section{Authors' contributions}

AAM participated in the study design, acquisition of data, data analysis, and manuscript writing. VC participated in manuscript writing and revision. BM participated in study design, manuscript writing and revision. PS participated in manuscript revision. MD participated in study design, data analysis, manuscript writing and revision. All authors read and approved the final manuscript.

\section{Acknowledgements}

The authors would like to thank Pierre Black for the development of the experimental setup as well as Geneviève Côté for providing support in the manuscript formatting.

\section{Author details}

'Université du Québec à Trois-Rivières, 3351 boul. des Forges, C.P. 500 Trois-Rivières, Québec G9A 5H7, Canada. ${ }^{2}$ University of Ontario Institute of Technology, 2000 Simcoe St North, Oshawa, Ontario L1H 7 K4, Canada. ${ }^{3}$ Canadian Memorial Chiropractic College, 6100 Leslie Street, Toronto, Ontario $\mathrm{M} 2 \mathrm{H} 3 \mathrm{~J} 1$, Canada.

Received: 3 February 2014 Accepted: 22 May 2014

Published: 26 May 2014

References

1. The international classification of headache disorders: 2 nd edition. Cephalalgia 2004, 24(1):9-160.

2. Stovner L, Hagen $K$, Jensen $R$, Katsarava $Z$, Lipton $R$, Scher A, Steiner T, Zwart JA: The global burden of headache: a documentation of headache prevalence and disability worldwide. Cephalalgia 2007, 27:193-210.

3. Rasmussen BK, Jensen R, Schroll M, Olesen J: Epidemiology of headache in a general population-a prevalence study. J Clin Epidemiol 1991, 44:1147-1157.

4. Russell MB, Levi N, Saltyte-Benth J, Fenger K: Tension-type headache in adolescents and adults: a population based study of 33,764 twins. Eur $J$ Epidemiol 2006, 21:153-160.

5. Smitherman TA, Burch R, Sheikh H, Loder E: The prevalence, impact, and treatment of migraine and severe headaches in the United States: a review of statistics from national surveillance studies. Headache 2013, 53:427-436

6. Bryans R, Descarreaux M, Duranleau M, Marcoux H, Potter B, Ruegg R, Shaw L, Watkin R, White E: Evidence-based guidelines for the chiropractic treatment of adults with headache. J Manipulative Physiol Ther 2011, 34:274-289.

7. Freitag F: Managing and treating tension-type headache. Med Clin North Am 2013, 97:281-292.

8. Passmore SR, Descarreaux M: Performance based objective outcome measures and spinal manipulation. J Electromyogr Kinesiol 2012, 22:697-707

9. Demoulin C, Crielaard JM, Vanderthommen M: Spinal muscle evaluation in healthy individuals and low-back-pain patients: a literature review. Joint Bone Spine 2007, 74:9-13.

10. O'Leary S, Jull G, Kim M, Vicenzino B: Cranio-cervical flexor muscle impairment at maximal, moderate, and low loads is a feature of neck pain. Man Ther 2007, 12:34-39.

11. Ylinen J, Hakkinen A, Nykanen M, Kautiainen H, Takala EP: Neck muscle training in the treatment of chronic neck pain: a three-year follow-up study. Eura Medicophys 2007, 43:161-169.

12. Abboud J, Marchand AA, Sorra K, Descarreaux M: Musculoskeletal physical outcome measures in individuals with tension-type headache: A scoping review. Cephalalgia 2013, 33:1319-1336.

13. Bendtsen L, Jensen R: Tension-type headache. Neurol Clin 2009, 27:525-535.

14. Bendtsen $L$ : Central sensitization in tension-type headache-possible pathophysiological mechanisms. Cephalalgia 2000, 20:486-508.

15. Hodges PW: Pain and motor control: From the laboratory to rehabilitation. J Electromyogr Kinesiol 2011, 21:220-228.

16. Zito G, Jull G, Story I: Clinical tests of musculoskeletal dysfunction in the diagnosis of cervicogenic headache. Man Ther 2006, 11:118-129.

17. Treleaven J, Jull G, LowChoy N: The relationship of cervical joint position error to balance and eye movement disturbances in persistent whiplash. Man Ther 2006, 11:99-106.

18. Newcomer KL, Laskowski ER, Yu B, Johnson JC, An KN: Differences in repositioning error among patients with low back pain compared with control subjects. Spine 2000, 25:2488-2493.

19. Warner JJ, Lephart S, Fu FH: Role of proprioception in pathoetiology of shoulder instability. Clin Orthop Relat Res 1996, 330:35-39. 
20. Sharma L, Pai YC: Impaired proprioception and osteoarthritis. Curr Opin Rheumatol 1997, 9:253-258.

21. Brumagne $S$, Cordo $P$, Verschueren S: Proprioceptive weighting changes in persons with low back pain and elderly persons during upright standing. Neurosci Lett 2004, 366:63-66.

22. Tsao H, Danneels LA, Hodges PW: ISSLS prize winner: Smudging the motor brain in young adults with recurrent low back pain. Spine 2011, 36:1721-1727.

23. Luomajoki H, Moseley GL: Tactile acuity and lumbopelvic motor control in patients with back pain and healthy controls. Br J Sports Med 2011 45:437-440

24. Brumagne S, Lysens $R$, Spaepen A: Lumbosacral position sense during pelvic tilting in men and women without low back pain: test development and reliability assessment. J Orthop Sports Phys Ther 1999, 29:345-351.

25. Heikkila HV, Wenngren Bl: Cervicocephalic kinesthetic sensibility, active range of cervical motion, and oculomotor function in patients with whiplash injury. Arch Phys Med Rehabil 1998, 79:1089-1094.

26. Treleaven J, Jull G, Sterling M: Dizziness and unsteadiness following whiplash injury: characteristic features and relationship with cervical joint position error. J Rehabil Med 2003, 35:36-43.

27. Lee HY, Wang JD, Yao G, Wang SF: Association between cervicocephalic kinesthetic sensibility and frequency of subclinical neck pain. Man Ther 2008, 13:419-425.

28. Amonoo-Kuofi HS: The density of muscle spindles in the medial intermediate and lateral columns of human intrinsic postvertebral muscles. J Anat 1983, 136:509-519.

29. Kulkarni V, Chandy MJ, Babu KS: Quantitative study of muscle spindles in suboccipital muscles of human foetuses. Neurol India 2001, 49:355-359.

30. Armstrong B, McNair $P$, Taylor D: Head and neck position sense. Sports Med 2008, 38:101-117.

31. Paulus I, Brumagne S: Altered interpretation of neck proprioceptive signals in persons with subclinical recurrent neck pain. $J$ Rehabil Med 2008, 40:426-432.

32. Treleaven J: Sensorimotor disturbances in neck disorders affecting postural stability, head and eye movement control. Man Ther 2008, 13:2-11

33. Revel M, Andre-Deshays C, Minguet M: Cervicocephalic kinesthetic sensibility in patients with cervical pain. Arch Phys Med Rehabil 1991, 72:288-291

34. Loudon JK, Ruhl M, Field E: Ability to reproduce head position after whiplash injury. Spine 1997, 22:865-868.

35. Pinsault N, Vaillant J, Virone $\mathrm{G}$, Caillat-Miousse $\mathrm{J}$, Lachens L, Vuillerme N: [Cervicocephalic relocation test: a study of performance stability] Ann Readapt Med Phys 2006, 49:647-651.

36. Grip H, Sundelin G, Gerdle B, Karlsson JS: Variations in the axis of motion during head repositioning-a comparison of subjects with whiplashassociated disorders or non-specific neck pain and healthy controls. Clin Biomech (Bristol, Avon) 2007, 22:865-873.

37. Descarreaux M, Passmore SR, Cantin V: Head movement kinematics during rapid aiming task performance in healthy and neck-pain participants: the importance of optimal task difficulty. Man Ther 2010, 15:445-450.

38. Jagacinski RJ, Monk DL: Fitts' Law in two dimensions with hand and head movements. J Mot Behav 1985, 17:77-95.

39. Passmore SR, Burke J, Lyons J: Older adults demonstrate reduced performance in a Fitts' task involving cervical spine movement. Adapt Phys Activ Q 2007, 24:352-363.

40. Fitts PM: The information capacity of the human motor system in controlling the amplitude of movement. J Exp Psychol 1954, 47:381-391.

41. Schmidt RA, Wrisberg CA: Motor learning and performance. 2 nd edition. Champaign, IL: Human Kinetics; 2000.

42. Magnoux E, Freeman MA, Zlotnik G: MIDAS and HIT-6 French translation: reliability and correlation between tests. Cephalalgia 2008, 28:26-34.

43. Wlodyka-Demaille S, Poiraudeau S, Catanzariti JF, Rannou F, Fermanian J, Revel M: French translation and validation of 3 functional disability scales for neck pain. Arch Phys Med Rehabil 2002, 83:376-382

44. Gauthier J, Bouchard S: Adaptation canadienne française de la forme révisée du State Trait Anxiety Inventory de Spielberger. Rev Can Sci Comport 1993, 25:559-578.

45. De Koning $\mathrm{CH}$, van den Heuvel SP, Staal JB, Smits-Engelsman BC, Hendriks EJ: Clinimetric evaluation of methods to measure muscle functioning in patients with non-specific neck pain: a systematic review. BMC Musculoskelet Disord 2008, 9:142.

46. Schmidt RA, Lee TD: Motor control and learning A behavioral emphasis. Champaign, Illinois: Human Kinetics; 2005.

47. Passmore SR, Burke JR, Good C, Lyons JL, Dunn AS: Spinal manipulation impacts cervical spine movement and fitts' task performance: a single-blind randomized before-after trial. J Manipulative Physiol Ther 2010, 33:189-192.

48. De Hertogh W, Vaes P, Beckwee D, Van Suijlekom H, Duquet W, Van Roy $P$ : Lack of impairment of kinaesthetic sensibility in cervicogenic headache patients. Cephalalgia 2007, 28:323-328.

49. Dumas JP, Arsenault AB, Boudreau G, Magnoux E, Lepage Y, Bellavance A, Loisel P: Physical impairments in cervicogenic headache: traumatic vs. nontraumatic onset. Cephalalgia 2001, 21:884-893.

50. Van Ettekoven $H$, Lucas C: Efficacy of physiotherapy including a craniocervical training programme for tension-type headache; a randomized clinical trial. Cephalalgia 2006, 26:983-991.

51. Youdas JW, Garrett TR, Suman VJ, Bogard CL, Hallman HO, Carey JR: Normal range of motion of the cervical spine: an initial goniometric study. Phys Ther 1992, 72:770-780.

52. Magis D, Vigano A, Sava S, D'Elia TS, Schoenen J, Coppola G: Pearls and pitfalls: Electrophysiology for primary headaches. Cephalalgia 2013, 33:526-539.

53. Pontell ME, Scali F, Marshall E, Enix D: The obliquus capitis inferior myodural bridge. Clin Anat 2013, 26:450-454.

54. Scali F, Pontell ME, Enix DE, Marshall E: Histological analysis of the rectus capitis posterior major's myodural bridge. Spine J 2013, 13:558-563.

55. Cullen KE: The neural encoding of self-generated and externally applied movement: implications for the perception of self-motion and spatial memory. Front Integr Neurosci 2014, 7:108

56. Moore DJ, Keogh E, Eccleston C: Headache impairs attentional performance. Pain 2013, 154:1840-1845.

doi:10.1186/1471-2474-15-179

Cite this article as: Marchand et al:: Is performance in goal oriented head movements altered in patients with tension type headache? BMC Musculoskeletal Disorders 2014 15:179.

\section{Submit your next manuscript to BioMed Central and take full advantage of:}

- Convenient online submission

- Thorough peer review

- No space constraints or color figure charges

- Immediate publication on acceptance

- Inclusion in PubMed, CAS, Scopus and Google Scholar

- Research which is freely available for redistribution 